\title{
Breast cancer recurrence following active treatment: determining its incidence in the NSW population
}

\section{Anna Kemp-Caseya,b,f, Elizabeth E Roughead ${ }^{b}$, Christobel Saundersc ${ }^{c}$, Frances Boyle ${ }^{\text {, }}$ Derrick Lopeza ${ }^{\text {, Max Bulsara }}{ }^{e}$ and David B Preena}

${ }^{a}$ Centre for Health Services Research, School of Population Health, The University of Western Australia, Perth

${ }^{b}$ Quality Use of Medicines and Pharmacy Research Centre, School of Pharmacy and Medical Sciences,

University of South Australia, Adelaide

'School of Surgery, The University of Western Australia, Perth

a Patricia Richie Centre for Cancer Care and Research, The Mater Hospital and The University of Sydney, NSW, Australia

e Institute for Health Research, University of Notre Dame, Fremantle, Western Australia

${ }^{\dagger}$ Corresponding author: anna.kemp@uwa.edu.au

\section{Article history}

Publication date: January 2016

Citation: Kemp-Casey A, Roughead EE, Saunders C, Boyle F, Lopez D, Bulsara M, Preen DB. Breast cancer recurrence following active treatment: determining its incidence in the NSW population. Public Health Res Pract. 2016;26(1):e2611607. doi: http://dx.doi.org/10.17061/phrp2611607

\section{Key points}

- Data on breast cancer recurrence are important to consumers, clinicians and health service planners but are not routinely collected or reported by any of Australia's state or territory cancer registries

- Using multiple linked health datasets, we determined that the annual incidence of recurrence between 18 months and 6 years after diagnosis was 3.3\%

- Recurrence after initial treatment for breast cancer was predicted by node status, hormone receptor status and tumour size at diagnosis

\section{Abstract}

Objectives: It is important for consumers, clinicians and health service planners to know the risk of recurrence of primary breast cancer after initial treatment. At present, none of Australia's state or territory cancer registries routinely report this information. We aimed to determine the incidence of recurrence in New South Wales (NSW) clinical practice for the period 18 months to 6 years after diagnosis of primary breast cancer.

Study type: Retrospective cohort study using population-based linked health data.

Methods: We identified 2416 women in the 45 and Up Study who were diagnosed with primary invasive breast cancer between 2003 and 2008 in NSW, and who had not had a recurrence 18 months after diagnosis. Unit-level hospital, pharmacy and outpatient medical claims were used to identify treatment for recurrence. Incidence of recurrence was calculated using individual person-time at risk (18 months to 6 years postdiagnosis), with follow-up censored for death or end of study period (median follow-up 3 years). Time to recurrence was calculated, and Cox proportional regression was used to identify women's baseline and active treatment characteristics that were predictive of recurrence up to 6 years postdiagnosis.

Results: 217 women (9\%) had a hospital, pharmacy or outpatient claim indicating breast cancer recurrence. Overall annual incidence of recurrence was 3.3\%. Recurrence rates were significantly higher for women with nodepositive (4.8\% vs $2.5 \%$ annually; hazard ratio $[\mathrm{HR}]=1.7 ; 95 \%$ confidence interval $[95 \% \mathrm{Cl}] 1.3,2.3)$ or hormone receptor-negative tumours $(3.8 \%$ vs $3.1 \%$ annually; $\mathrm{HR}=1.3 ; 95 \% \mathrm{Cl} 1.0,1.7$ ). Women with tumours $>2 \mathrm{~cm}$ at diagnosis were more likely to experience recurrence than women with smaller/unknown tumours (4.8\% vs $2.7 \%$ annually; $\mathrm{HR}=1.5 ; 95 \% \mathrm{Cl} 1.1,2.0$ ). 
Conclusions: A combination of routinely collected administrative health datasets can be used to determine recurrence rates, allowing future assessment of population-level changes over time and investigations of the real-world impact of specific treatments on outcomes.

\section{Introduction}

Outcomes for the majority of women diagnosed with primary breast cancer are good, with 5-year survival more than $80 \% .{ }^{1}$ However, some women will progress to more advanced disease and ultimately die of their cancer. Active treatment for primary breast cancer typically involves surgical removal of a tumour and a course of radiotherapy and/or chemotherapy ${ }^{2}$, all of which would normally be completed within 18 months of diagnosis. Recurrence refers to the return of cancer after active treatment and a cancer-free period. ${ }^{3}$ Breast cancer may return to the same or the other breast (local recurrence), chest wall or lymph nodes (regionalised recurrence), or elsewhere in the body (distant metastasis). ${ }^{2}$ When detected, recurrence may be treated with surgery, radiotherapy, chemotherapy and pharmacotherapy. ${ }^{2}$ The risk of recurrence is known to be higher for women with node-positive ${ }^{4}$, human epidermal growth factor receptor 2 (HER2)-positive ${ }^{5}$ and hormone receptornegative ${ }^{6}$ tumours, and with increasing tumour size. ${ }^{7}$ Understandably, recurrence is of utmost concern for women diagnosed with primary cancer. ${ }^{8}$

Timely and accurate data on the incidence of recurrence are also of high importance to clinicians and health service planners, and could assist in treatment decision making and assessment of treatment outcomes. ${ }^{9-11}$ To date, none of Australia's state or territory cancer registries routinely collect or report statistics on recurrence. ${ }^{12-19}$ The New South Wales (NSW) Cancer Registry collects information on 'new episodes of active treatment' in hospitals ${ }^{13}$ for individuals with previously reported tumours, and this has been used as a proxy measure of breast cancer recurrence. ${ }^{9}$ However, these data are not available to researchers ${ }^{12}$ and exclude women treated outside the hospital system (i.e. those receiving pharmacotherapy or radiotherapy only, administered on an outpatient basis in NSW). In addition, few state or territory registries collect information on clinical factors that are likely to affect recurrence, such as HER2 and hormone receptor status, and the type of initial treatment received (e.g. chemotherapy, surgery). ${ }^{9}$

To date, only one research group has obtained data on new episodes of treatment from the NSW Cancer Registry ${ }^{9}$, which were used to estimate rates of progression to distant metastasis (metastatic breast cancer). Lord and colleagues ${ }^{9}$ estimated the 5-year cumulative incidence of metastatic cancer among 6644 women diagnosed with primary breast cancer in NSW in 2001-2002. Women without a NSW hospital admission between 2001 and 2007 were excluded from the study, and follow-up was not censored for metastasis or death (i.e. person-time at risk was not calculated). The impact of tumour size, HER2 status, hormone receptor status and initial treatment could not be examined with available data. The authors reported an overall 5-year cumulative incidence of $10 \%$ ( $2 \%$ per year). Their study currently provides the only Australian population-based data for breast cancer recurrence and is one of the few international studies to estimate recurrence outside of clinical trials. ${ }^{9}$ However, it is likely to underestimate the true incidence of breast cancer recurrence because local and regionalised recurrences were not captured, and women not receiving hospital treatment were excluded. ${ }^{9}$

Australia has several linkable, whole-population administrative health datasets available to researchers that can potentially be used to estimate breast cancer recurrence rates, and which contain information about tumour characteristics and initial therapy that is not routinely collected by registries. For example, Pharmaceutical Benefits Scheme (PBS) claims can be used to determine whether women have been dispensed trastuzumab for primary HER2-positive tumours, endocrine therapy for hormone receptor-positive tumours, or a therapy restricted for use in those with advanced breast cancer. ${ }^{20}$

This study aimed to determine population-based estimates of recurrence in the period following completion of active treatment for primary breast cancer (18 months to 6 years postdiagnosis).

\section{Methods}

\section{Study population}

The cohort was selected from women enrolled in the Sax Institute's 45 and Up Study, a cohort of approximately 267000 adults (143 014 women) aged $\geq 45$ years residing in NSW, Australia. ${ }^{21}$ Participants joined the study between January 2006 and December 2009. ${ }^{22,23}$ Although the cohort was derived from the general population, the modest response fraction (18\%) means that it is not likely to represent the NSW population. ${ }^{21,24}$ Information regarding the establishment and recruitment of the cohort is described elsewhere. ${ }^{21}$

Our study population included women in the 45 and Up Study with a diagnosis of invasive breast cancer recorded on the NSW Cancer Registry between 1 January 2003 and 31 December 2008. Women were excluded if they had metastatic cancer or unknown tumour stage at diagnosis (because these women may have had metastases) $(n=189)$, or if they experienced 
recurrence within 18 months of diagnosis $(n=35)$. The final number of participants was 2416. Of these, $289(12 \%)$ were diagnosed before joining the 45 and Up Study (median time from diagnosis to recruitment 5.6 months). None of the women in the cohort had a new primary invasive tumour recorded on the NSW Cancer Registry between 2003 and 2008 (end of available NSW Cancer Registry data). Women were followed from 18 months postdiagnosis until recurrence, death or end of data (30 June 2010), whichever occurred first. Follow-up commenced at 18 months (considered to be the end of the active treatment phase) to avoid the immortal time bias inherent in comparing outcomes for women undergoing different treatments after diagnosis. The study period was defined as 1 July 2004 to 30 June 2010, and median follow-up was 3 years (25th-75th percentiles $=1.5-4.4$ years) .

\section{Data sources and linkage}

We accessed unit-record, linked data from i) the 45 and Up Study baseline survey, ii) the NSW Cancer Registry, iii) the NSW Admitted Patient Data Collection (all admissions to public and private hospitals), iv) PBS claims (all subsidised medicines), v) Medicare Benefits Schedule (MBS) claims (all subsidised outpatient consultations and investigations), and vi) the NSW Registry of Births, Deaths and Marriages (all deaths in NSW) (Table 1). PBS and MBS data were supplied by the Australian Government Department of Human Services and deterministically linked to the 45 and Up Study baseline data. The remaining datasets were probabilistically linked by the NSW Centre for Health Record Linkage ${ }^{25}$, with quality audits showing fewer than $0.5 \%$ false positive links. ${ }^{26}$

\section{Ethics}

Participants were drawn from the 45 and Up Study cohort. All cohort members provided written consent to join the 45 and Up Study, to have their routinely collected health data linked, and for these data to be provided to thirdparty researchers for approved projects. This consent procedure was approved by the University of New South Wales Human Research Ethics Committee and the Australian Government Department of Health. The current study also received approval from the University of Western Australia Human Research Ethics Committee (approval RA/4/1/4589), and the NSW Population and Health Services Research Ethics Committee (approval HREC/11/CIPHS/35).

\section{Ascertaining incidence of breast cancer recurrence}

We ascertained recurrence from i) specified surgeries, chemotherapy or radiotherapy occurring for the first time 18 months or more after the date of diagnosis, or at least 12 months after previous claims for either surgery, chemotherapy or radiotherapy (indicating a new round of treatment); or ii) first dispensing of a medicine indicated only for 'advanced' or 'metastatic' breast cancer during the study period ${ }^{20}$ (Table 2). The time between 18 months postdiagnosis and end of follow-up (or censoring date) was used to calculate person-time at risk for each participant.

\section{Demographic, clinical and initial treatment characteristics}

To optimise comparability with previously reported data from an Australian setting, we examined demographic and clinical subgroups using the same categories as Lord and colleagues. ${ }^{9}$ Women's age (<50, 50-69, $\geq 70$ years), node status (positive 'localised tumours', negative 'regionalised tumours'), morphology (invasive ductal, lobular, other), tumour size ( $>2 \mathrm{~cm}, \leq 2 \mathrm{~cm}$ or unknown), area of residence (major city, other) and social disadvantage at diagnosis (least, middle, most) were obtained from the NSW Cancer Registry. Country of birth was reported by participants in the 45 and Up Study baseline survey (Australia or New Zealand, other).

Table 1. Description, available dates and population coverage of data sources used for this study

\begin{tabular}{|c|c|c|c|}
\hline Dataset & Description & Date range available & Population covered \\
\hline $\begin{array}{l}45 \text { and Up Study baseline } \\
\text { survey }\end{array}$ & $\begin{array}{l}\text { Self-reported health and lifestyle } \\
\text { information from participants at study } \\
\text { recruitment }\end{array}$ & $\begin{array}{l}\text { January } 2006 \text { - December } \\
2009 \text { (recruitment period) }\end{array}$ & $\begin{array}{l}\text { Participants in the NSW } 45 \\
\text { and Up Study }(N \sim 270000)\end{array}$ \\
\hline NSW Central Cancer Registry & $\begin{array}{l}\text { New diagnoses of malignant } \\
\text { neoplasms }\end{array}$ & $\begin{array}{l}\text { January } 2003 \text { - December } \\
2008\end{array}$ & Whole population (NSW) \\
\hline $\begin{array}{l}\text { Admitted Patient Data } \\
\text { Collection }\end{array}$ & $\begin{array}{l}\text { Admissions to public and private } \\
\text { hospitals }\end{array}$ & January 2003 - June 2010 & Whole population (NSW) \\
\hline $\begin{array}{l}\text { Pharmaceutical Benefits } \\
\text { Scheme }\end{array}$ & $\begin{array}{l}\text { Subsidised prescription medicines } \\
\text { dispensed }\end{array}$ & January 2003 - June 2010 & Whole population (Australia) \\
\hline Medicare Benefits Schedule & $\begin{array}{l}\text { Subsidised outpatient consultations } \\
\text { and investigations }\end{array}$ & January 2003 - June 2010 & Whole population (Australia) \\
\hline $\begin{array}{l}\text { NSW Registry of Births, Deaths } \\
\text { and Marriages }\end{array}$ & Deaths occurring in NSW & January 2003 - June 2010 & Whole population (NSW) \\
\hline
\end{tabular}


Table 2. Hospital, outpatient and pharmacy claims used to identify breast cancer recurrence, by data source

\begin{tabular}{lll}
\hline Data source & Claim description and code & Timing of claim \\
\hline Admitted Patient & Lumpectomy $(31500$, & First-time claim \\
Data Collection & $31503,31506,31509$, & $>18$ months \\
& $31512) ;$ mastectomy & from diagnosis \\
& $(31518,31524) ;$ & or repeat claim \\
chemotherapy (13915, & $>12$ months \\
& $13918,13921,13924$, & from previous \\
& 13927,1393013933, & claim
\end{tabular}

Medicare

Benefits

Schedule 13936)

First-time claim

$>18$ months from diagnosis or repeat claim $>12$ months from previous claim 15219-15232, 1523415247, 15249-15262, 15264-15272, 1530315337, 15339-15357)

Pharmaceutical Capecitabine (8362D, Benefits Scheme 8631C); lapatinib (9148L); after diagnosis medroxyprogesterone (2728N); megestrol (2734X); toremifene (8216K); vinorelbine (8280T, 8281W, 9009E, 9010F)

The initial treatment characteristics examined within 18 months of diagnosis were i) dispensing of trastuzumab (a proxy for HER2-positive status), ii) dispensing of endocrine therapy (a proxy for hormone receptor-positive status), iii) initial surgery type, and iv) chemotherapy. PBS data were used to determine whether participants had been dispensed trastuzumab (4632T, 4639E) or a first-line endocrine therapy (anastrozole 8179L; letrozole 8245Y; tamoxifen 2109B, 2110C) within 18 months of diagnosis. PBS supply of trastuzumab is restricted to women with primary HER2-positive tumours; and anastrozole, letrozole and tamoxifen are restricted to women with hormonedependent tumours. ${ }^{20,}{ }^{27}$ Hospital claims were used to identify the first breast cancer surgery women underwent within 18 months of diagnosis (lumpectomy, mastectomy, none; Table 2). MBS and hospital records were used to identify whether chemotherapy was administered within 18 months of diagnosis.

\section{Statistical analysis}

The number and proportion of all participants with different baseline characteristics were calculated. Annual incidence rates were calculated by dividing the number of incident cases of recurrence by the total person-years at risk. Annual incidence was calculated for all women, and by baseline and initial treatment characteristics. Kaplan-Meier curves were used to determine the time from end of active treatment and recurrence, stratified by node status at diagnosis. Univariate Cox proportional hazards regression analysis was used to determine the rate of recurrence for women with different baseline and initial treatment characteristics. Within each characteristic examined, the group with the lowest annual incidence was used as the referent. Multivariate Cox modelling was also conducted to determine which characteristics independently predicted recurrence. For each variable in the Cox models, the proportional hazards assumption was tested visually using Kaplan-Meier curves and by examining a plot of -log(-log(survival time)) against time. For comparability with previous Australian research ${ }^{9}$, we initially included all variables in the multivariate model and used backward stepwise elimination to derive the final most parsimonious model. Hazard ratios (HRs) and 95\% confidence intervals $(95 \% \mathrm{Cl})$ were calculated for each characteristic. All analyses were conducted using SPSS version 19

\section{Results}

\section{Time to recurrence}

Of the 2416 women diagnosed with primary invasive breast cancer, 217 (9\%) had a hospital, MBS or PBS claim indicating recurrence during the study period. From 18 to 30 months postdiagnosis, the cumulative incidence of recurrence for all women was $4 \%$, rising to $11.9 \%$ by 66 months (Figure 1). When stratifying time to recurrence by node status, it was apparent that women with nodepositive tumours had substantially higher cumulative incidence of recurrence at each time point than women with node-negative tumours.

\section{Unadjusted regression analyses}

Women with node-positive tumours at diagnosis had significantly higher annual recurrence rates than women who had node-negative tumours $(4.8 \%$ vs $2.5 \%$, $p<0.001$; Table 3). Recurrence rates were also higher for women with tumours $>2 \mathrm{~cm}$ at diagnosis compared with other women $(4.8 \%$ vs $2.7 \%$ per year, $p<0.001)$. Women who initially had chemotherapy had higher rates of recurrence than women who did not $(4.4 \%$ vs $3.0 \%$ per year, $p=0.015)$, as did women undergoing mastectomy compared with lumpectomy (4.6\% vs $3.0 \%$ per year, $p=0.019$ ). There was no significant difference in recurrence between women with hormone receptornegative tumours and those with receptor-positive tumours (3.8\% vs $3.1 \%$ per year; $p=0.151)$. HER2 status was not significantly associated with differences in recurrence rates. We did not find any difference in recurrence rates based on women's age, tumour morphology, area of residence, social disadvantage or birth country. 
Figure 1. Kaplan-Meier curve showing time to breast cancer recurrence for all women and by node status at diagnosis

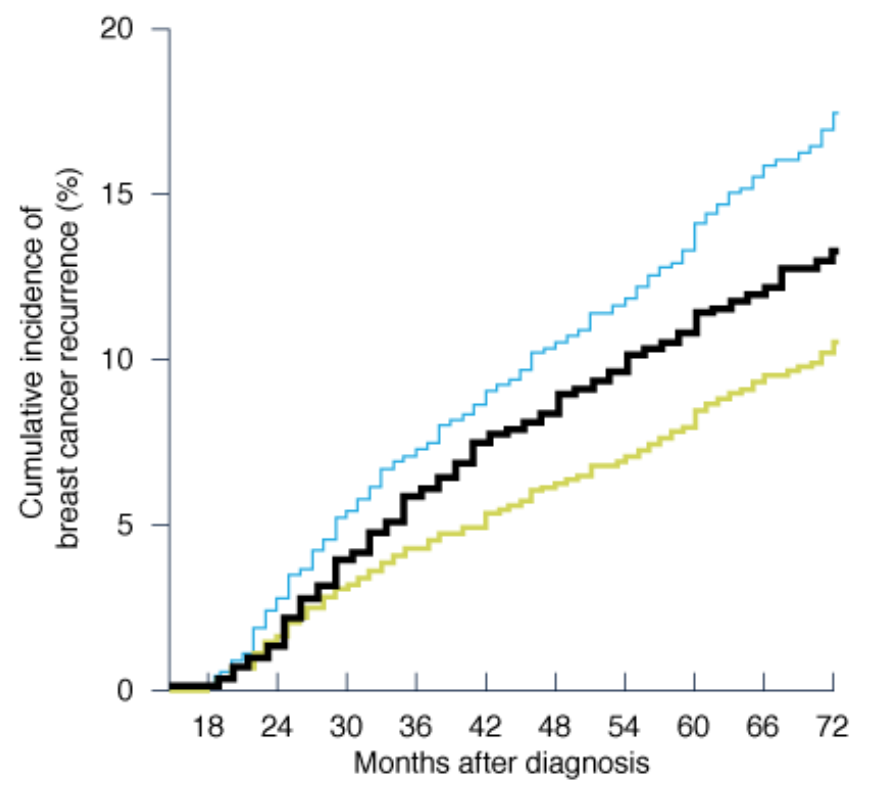

- Node positive - All women

- Node negative

\section{Adjusted regression analyses}

Multivariate Cox regression analysis, which initially included all variables from the univariate modelling, resulted in a final model showing that women with node-positive tumours were $73 \%$ more likely to develop recurrent cancer than those diagnosed with nodenegative tumours $(\mathrm{HR}=1.7 ; 95 \% \mathrm{Cl} 1.3,2.3$; Table 3$)$. Women with tumours $>2 \mathrm{~cm}$ at baseline had a $52 \%$ higher chance of recurrence than other women $(H R=1.5$; $95 \% \mathrm{Cl} 1.1$ 2.0). Hormone receptor status predicted recurrence risk after adjusting for other variables, with recurrence $33 \%$ more likely for women with receptornegative tumours $(H R=1.3 ; 95 \% \mathrm{Cl} 1.0,1.7)$. No other variables, including initial chemotherapy or initial surgery, had a significant effect on incidence of recurrence in the multivariate model.

\section{Discussion}

Using multiple routinely collected health datasets, we found that NSW women diagnosed with primary breast cancer developed recurrent breast cancer at a rate of 3.3\% per year in the period between 18 months and 6 years postdiagnosis. This is considerably higher than the metastatic breast cancer incidence that Lord and colleagues identified from NSW Cancer Registry data ${ }^{9}$ (2.0\% per year). In keeping with previous Australian data $^{9}$, we found that recurrence was independently predicted by node status, but did not find a relationship with age or social disadvantage. Our finding that recurrence risk is greater for women with node-positive or hormone receptor-negative tumours after adjustment for other variables is consistent with existing international evidence. ${ }^{4-6}$ Recurrence estimates are likely higher in our study than previously reported by Lord and colleagues because of our capture of local and regionalised recurrences in addition to distant metastases. We also captured recurrence treated outside of hospitals, and did not begin following women until 18 months postdiagnosis, when active treatment was complete.

We did not find higher risk of recurrence for women with HER2-positive tumours, despite clinical trial evidence that this is a strong predictor of recurrence.$^{28}$ It is likely that we underascertained women with HER2-positive tumours, because only $5 \%$ of our cohort was dispensed trastuzumab, and approximately $25 \%$ of women diagnosed with breast cancer are reported to have HER2positive tumours. ${ }^{29}$ Trastuzumab was not PBS-listed for primary HER2-positive tumours until October 2006 and was therefore unavailable to the women in our study who completed active treatment earlier (62\% of our sample), possibly explaining this finding. ${ }^{27}$

\section{Strengths and weaknesses}

To our knowledge, this is the first study to determine recurrence incidence rates, rather than cumulative incidence, in the years following active treatment for primary breast cancer in Australian clinical practice. This is also the first study to examine the influence of initial treatment on rates of recurrence in Australian practice. A further novel aspect of this study is ascertainment of recurrence using datasets and variables that are widely available to researchers, allowing ongoing monitoring of recurrence rates over time in the absence of routinely collected or available recurrence data from Australia's cancer registries. We used health records for a heterogeneous community sample for which all hospital admissions and publicly subsidised medicines and outpatient services had been captured.

There are limitations to this study. We were not able to directly assess breast cancer recurrence because of the unavailability of such data, and had to combine records from multiple datasets on surgeries, medicines and services used to treat recurrence. Our group has previously used this method to determine recurrence ${ }^{30}$, as have a number of studies in the US. ${ }^{10,31}$ A US study was able to assess the validity of this method against chart review, and reported sensitivity and specificity of $92 \%$ and $94 \%$, respectively. ${ }^{31}$ We could not differentiate between local and regionalised recurrence and distant metastasis, and did not have access to the relevant NSW Cancer Registry data to validate metastatic cases. We were also unable to differentiate between new primary tumours and recurrences occurring after the end of NSW Cancer Registry data in December 2008. Finally, we were not able to ascertain surgeries or inpatient radiotherapy and chemotherapy administered outside NSW (for women who sought treatment in another state). Despite these limitations, our overall results and patterns observed in 
Table 3. Baseline characteristics of 2416 women diagnosed with primary invasive breast cancer between 2003 and 2008, and incidence rates and hazard ratios for 217 women with breast cancer recurrence in the period 18 months to 6 years postdiagnosis, by baseline and initial treatment characteristics

\begin{tabular}{|c|c|c|c|c|c|c|}
\hline \multirow[b]{2}{*}{ Characteristic } & \multirow[b]{2}{*}{ Category } & \multirow{2}{*}{$\begin{array}{c}\text { All women } \\
n(\%)\end{array}$} & \multicolumn{4}{|c|}{ Women with breast cancer recurrence } \\
\hline & & & $\begin{array}{c}n \text { of cases/ } \\
\text { person-years at } \\
\text { risk }\end{array}$ & $\begin{array}{c}\text { Annual incidence } \\
(\%)\end{array}$ & $\begin{array}{c}\text { Unadjusted } \\
\text { hazard ratio } \\
(95 \% \mathrm{Cl})\end{array}$ & $\begin{array}{c}\text { Adjusted hazard } \\
\text { ratio }(95 \% \mathrm{Cl})^{\mathrm{a}}\end{array}$ \\
\hline \multirow[t]{3}{*}{ Age at diagnosis } & $<50$ years & $401(16.6)$ & $45 / 1164$ & 3.9 & $1.47(0.93-2.31)$ & na \\
\hline & $50-69$ years & $1555(64.4)$ & $140 / 4193$ & 3.3 & $1.26(0.86-1.85)$ & na \\
\hline & $\geq 70$ years & $460(19.0)$ & $32 / 1202$ & 2.7 & 1.00 & na \\
\hline \multirow[t]{2}{*}{ Node status } & Positive & $908(37.6)$ & $110 / 2313$ & 4.8 & $1.86(1.43-2.43)$ & $1.73(1.31-2.28)$ \\
\hline & Negative & $1508(62.4)$ & $107 / 4246$ & 2.5 & 1.00 & 1.00 \\
\hline \multirow[t]{3}{*}{ Morphology } & Invasive ductal & $1812(75.0)$ & $164 / 4932$ & 3.3 & $1.06(0.69-1.62)$ & na \\
\hline & Lobular & $307(12.7)$ & 29/866 & 3.4 & $1.07(0.62-1.84)$ & na \\
\hline & Other & $297(12.3)$ & $24 / 761$ & 3.2 & 1.00 & na \\
\hline \multirow{2}{*}{$\begin{array}{l}\text { Area of } \\
\text { residence }\end{array}$} & Major city & $1295(53.6)$ & $121 / 3509$ & 3.4 & $1.10(0.84-1.43)$ & na \\
\hline & Regional/remote & $1121(46.4)$ & $96 / 3050$ & 3.1 & 1.00 & na \\
\hline \multirow{3}{*}{$\begin{array}{l}\text { Social } \\
\text { disadvantage }\end{array}$} & Least & $506(20.9)$ & $41 / 1375$ & 3.0 & 1.00 & na \\
\hline & Middle & $906(37.5)$ & $72 / 2427$ & 3.0 & $0.99(0.68-1.46)$ & na \\
\hline & Most & $1004(41.6)$ & $104 / 2757$ & 3.8 & 1.27 (0.88-1.82) & na \\
\hline \multirow[t]{2}{*}{ Country of birth } & $\begin{array}{l}\text { Australia/ } \\
\text { New Zealand }\end{array}$ & $1882(77.9)$ & $160 / 5138$ & 3.1 & 1.00 & na \\
\hline & Other & $534(22.1)$ & $57 / 1421$ & 4.0 & $1.29(0.95-1.74)$ & na \\
\hline \multirow[t]{2}{*}{ Tumour size } & $>2 \mathrm{~cm}$ & $788(32.6)$ & $86 / 1789$ & 4.8 & $1.72(1.31-2.27)$ & $1.52(1.14-2.03)$ \\
\hline & $\leq 2 \mathrm{~cm} /$ unknown & $1628(67.4)$ & $131 / 4770$ & 2.7 & 1.00 & 1.00 \\
\hline \multirow[t]{2}{*}{ HER2 status ${ }^{b}$} & Positive & $125(5.2)$ & $11 / 194$ & 5.7 & $1.60(0.87-2.95)$ & na \\
\hline & Negative & 2291 (94.8) & 206/6365 & 3.2 & 1.00 & na \\
\hline \multirow{2}{*}{$\begin{array}{l}\text { Hormone } \\
\text { receptor status }\end{array}$} & Positive & $1600(66.2)$ & $133 / 4321$ & 3.1 & 1.00 & 1.00 \\
\hline & Negative & $816(33.8)$ & $84 / 2238$ & 3.8 & $1.22(0.93-1.61)$ & $1.33(1.01-1.74)$ \\
\hline \multirow[t]{3}{*}{ Initial surgeryc } & Lumpectomy & $1223(50.6)$ & $78 / 2636$ & 3.0 & 1.00 & na \\
\hline & Mastectomy & $501(20.8)$ & $47 / 1032$ & 4.6 & $1.54(1.07-2.21)$ & na \\
\hline & None & $692(28.6)$ & $92 / 2891$ & 3.2 & $1.15(0.84-1.58)$ & na \\
\hline \multirow{2}{*}{$\begin{array}{l}\text { Initial } \\
\text { chemotherapyc }\end{array}$} & Yes & $743(30.8)$ & $70 / 1601$ & 4.4 & $1.43(1.07-1.91)$ & na \\
\hline & No & $1673(69.2)$ & $147 / 4958$ & 3.0 & 1.00 & na \\
\hline
\end{tabular}

95\% Cl = 95\% confidence interval; HER2 = human epidermal growth factor receptor 2; na = not applicable

a All variables were initially included in the adjusted model, and backward stepwise elimination was used until only significant variables remained.

b Determined by dispensing of trastuzumab for HER2 status, and either anastrozole, letrozole or tamoxifen for hormone receptor status, within

18 months of diagnosis.

c Within 18 months of diagnosis.

Note: Cells in bold indicate $95 \% \mathrm{Cls}$ that do not cross the null value.

participant subgroups are similar to (but higher than) those reported previously from this source. ${ }^{9}$

Our sample was drawn from the 45 and Up Study, limiting the cohort to individuals aged $\geq 45$ years at the time of recruitment to the study. The study had a relatively modest response fraction; however, direct representativeness is not required to demonstrate valid relationships between exposures and outcomes ${ }^{32}$, and previous work has demonstrated that internal comparisons from this cohort are valid and reliable. ${ }^{24}$ Although primary breast cancer is usually diagnosed in women in their sixties ${ }^{33}$, young women, who are more likely to have aggressive cancers, are under-represented in our study. ${ }^{34}$ We could not directly ascertain whether women in our cohort had HER2-positive or hormone receptor-positive tumours; however, trastuzumab and the endocrine therapies were only PBS-subsidised for women with these respective characteristics during the study period. 


\section{Conclusion}

Our results indicate that women with primary breast cancer in NSW practice develop recurrent breast cancer at the rate of $3.3 \%$ annually in the period 18 months to 6 years after diagnosis - substantially higher than the $2.0 \%$ annually reported previously. ${ }^{9}$ In a 2007 Australian survey, consumers reported 'up-to-date information' and 'managing concerns about cancer coming back' as among their greatest unmet needs ${ }^{8}$, highlighting the need for timely and accurate recurrence data from Australian practice. The method we report for ascertaining breast cancer recurrence can be used to assess populationlevel changes over time and to investigate the real-world impact of specific treatments on outcomes in the absence of available Cancer Registry data on recurrence.

\section{Acknowledgements}

This research was completed using data collected through the 45 and Up Study (www.saxinstitute.org.au). The 45 and Up Study is managed by the Sax Institute in collaboration with major partner Cancer Council NSW; and partners the National Heart Foundation of Australia (NSW Division); the NSW Ministry of Health; NSW Family \& Community Services - Ageing, Disability \& Home Care; and the Australian Red Cross Blood Service. We thank the many thousands of people participating in the 45 and Up Study. The authors wish to thank staff at the NSW Centre for Health Record Linkage, as well as data custodians the NSW Cancer Institute, the NSW Ministry of Health, NSW Justice and Attorney General, the Australian Bureau of Statistics, and the Australian Government Department of Human Services. This study was jointly funded by Cancer Australia and the National Breast Cancer Foundation.

\section{Competing Interests}

None declared

\section{Author contributions}

AKC, CS and ER conceived the study and interpreted data. AKC performed the statistical analyses and drafted the manuscript. MB and DL aided with data interpretation and critically reviewed the statistical content of the manuscript. DP, CS, FB and MB assisted with acquisition of data and critically reviewed the manuscript. All authors read and approved the final manuscript and are accountable for all aspects of the work.

\section{References}

1. Howlader N, Noone AM, Krapcho M, Garshell J, Neyman N, Altekruse SF, et al. SEER cancer statistics review, 1975-2010. Bethesda, MD: National Cancer Institute; 2013 [cited 2015 Aug 13]. Available from: www. seer.cancer.gov/archive/csr/1975_2010/results_merged/ sect_04_breast.pdf

2. Cancer Australia. Shared follow-up care. Sydney: Cancer Australia; 2015 [cited 2015 Oct 16]. Available from: www. canceraustralia.gov.au/affected-cancer/cancer-types/ breast-cancer/life-after-breast-cancer/shared-follow-care

3. American Cancer Society. When cancer comes back: cancer recurrence. Atlanta, GA: American Cancer Society; 2015 [cited 2015 Oct 16]. Available from: www.cancer.org/acs/groups/cid/documents/ webcontent/002947-pdf.pdf

4. Rack B, Janni W, Gerber B, Strobl B, Schindlbeck C, Klanner E, et al. Patients with recurrent breast cancer: does the primary axillary lymph node status predict more aggressive tumor progression? Breast Cancer Res Treat. 2003;82(2):83-92.

5. Hess KR, Esteva FJ. Effect of HER2 status on distant recurrence in early stage breast cancer. Breast Cancer Res Treat. 2013;137(2):449-55.

6. Yu K, Wu J, Shen Z, Shao Z. Hazard of breast cancerspecific mortality among women with estrogen receptor-positive breast cancer after five years from diagnosis: implication for extended endocrine therapy. J Clin Endocrinol Metab. 2012;97(12):E2201-9.

7. Cianfrocca M, Goldstein LJ. Prognostic and predictive factors in early-stage breast cancer. Oncologist. 2004;9(6):606-16.

8. Hodgkinson K, Butow P, Hunt G, Pendlebury S, Hobbs K, Wain $G$. Breast cancer survivors' supportive care needs 2-10 years after diagnosis. Support Care Cancer. 2007; 15:(5)515-23.

9. Lord S, Marinovich M, Patterson J, Wilcken N, Kiely B, Gebski V, et al. Incidence of metastatic breast cancer in an Australian population-based cohort of women with non-metastatic breast cancer at diagnosis. Med J Aust. 2012;196(11):688-92.

10. Stokes M, Thompson D, Montoya EL, Weinstein MC, Winer EP, Earle CC. Ten-year survival and cost following breast cancer recurrence: Estimates from SEERMedicare data. Value Health. 2008;11(2):213-20.

11. iSource National Breast Cancer Centre Advanced Breast Cancer Working Group. Clinical practice guidelines for the management of advanced breast cancer. Canberra: National Health and Medical Research Council, Commonwealth of Australia; 2001 [cited 2015 Oct 29]. Available from: www.nhmrc.gov.au/_files_nhmrc/ publications/attachments/cp76_management_advanced_ breast_cancer_131223.pdf 
12. NSW Central Cancer Registry. NSW Central Cancer Registry data dictionary. Sydney: Cancer Institute NSW; 2014 [cited 2015 Jun 26]. Available from: www. cancerinstitute.org.au/media/165425/nsw-central-cancerregistry-data-dictionary.pdf

13. Ministry of Health, NSW. Cancer Registry - notifying cancer cases to the NSW Central Cancer Registry. Sydney: NSW Health; 2009 [cited 2015 Jun 26]. Available from: www0.health.nsw.gov.au/policies/pd/2009/pdf/ PD2009_012.pdf

14. Northern Territory Cancer Registry. Northern Territory Cancer Register: data collection, analysis and reporting procedures. Darwin: NT Department of Health and Community Services; 2004 [cited 2015 Jun 26]. Available from: digitallibrary.health.nt.gov.au/prodjspui/ bitstream/10137/61/1/cancer_register_data_collection.pdf

15. Queensland Cancer Registry. Queensland Cancer Registry instruction manual for notifying cancer: HBCIS hospitals. Brisbane: Cancer Council Queensland; 2009 [cited2015 Jun 26]. Available from: www.cancerqld. org.au/page/Research_statistics/queensland_cancer_ registry/QCR_public_hospital_notifications/

16. Queensland Cancer Registry. Access to data for researchers. Brisbane: Cancer Council Queensland [cited 2015 Jun 26]. Available from: www.cancerqld.org. au/page/research_statistics/queensland_cancer_registry/

17. Population Health Research Network. Brisbane: the Network; c2011 [cited 2015 Jun 26]. Data collections available: South Australia; [about 9 screens]. Available from: www.phrn.org.au/for-researchers/data-collectionsavailable/south-australia/

18. Menzies Institute for Medical Research. Tasmanian Cancer Registry. Hobart: University of Tasmania; 2008 [cited 2015 Jun 26]. Available from: www.menzies.utas. edu.au/article. php?Doo $=$ ContentView\&id $=920$

19. Western Australian Government. Health (Western Australian Cancer Register) regulations. Perth: Government of Western Australia; 2011 [cited 2015 Jun 25]. Available from: www.health.wa.gov.au/ wacr/docs/CurrentRegulations_Detail.pdf

20. Australian Government Department of Health and Ageing. Schedule of pharmaceutical benefits, 1 April -30 April 2010. Canberra: Australian Government; 2010 [cited 2010 Aug 12]. Available from: www.pbs.gov.au/publication/ schedule/2010/2010-04-01-general-schedule.pdf

21. 45 and Up Study Collaborators, Banks E, Redman S, Jorm L, Armstrong B, Bauman A, et al. Cohort profile: The 45 and Up Study. Int J Epidemiol. 2008;37(5):941-7.

22. Banks E, Jorm L, Wutzke S. The 45 and Up Study: fostering population health research in NSW. N S W Public Health Bull. 2011;22(2):1516.
23. Sax Institute. Sydney: The Institute. Researcher toolkit; c2005 [cited 2013 Oct 31]. Available from: www. saxinstitute.org.au/our-work/45-up-study/for-researchers/

24. Mealing N, Banks E, Jorm L, Steel D, Clements M, Rogers KD. Investigation of relative risk estimates from studies of the same population with contrasting response rates and designs. BMC Med Res Methodol. 2010;10:26.

25. CHeReL: Centre for Health Record Linkage. Sydney: CHeReL; c2011 [cited 2012 Jun 6]. Available from: www.cherel.org.au

26. Centre for Health Record Linkage. Sydney: The Centre; c2011 [cited 2015 Oct 16]. Quality assurance; [about 4 screens]. Available from: www.cherel.org.au/qualityassurance

27. Pharmaceutical Benefits Scheme. Canberra: Australian Government Department of Health; 2006 Oct 1 [cited 2015 Jun 24]. Listing of Herceptin on the PBS Canberra; [about 4 screens]. Available from: www.pbs.gov.au/info/ news/2006/10/listing-of-herceptin

28. Anderson WF, Chen BE, Jatoi I, Rosenberg PS. Effects of estrogen receptor expression and histopathology on annual hazard rates of death from breast cancer. Breast Cancer Res Treat. 2006;100:121-6.

29. Viani GA, Afonso SL, Stefano EJ, De Fendi LI, Soares FV. Adjuvant trastuzumab in the treatment of her-2-positive early breast cancer: a meta-analysis of published randomized trials. BMC Cancer. 2007;7:153.

30. Kemp A, Preen DB, Saunders C, Boyle F, Bulsara M, Malacova E, Roughead EE. Early discontinuation of endocrine therapy for breast cancer: who is at risk in clinical practice? Springerplus. 2014;3:282.

31. Earle CC, Nattinger AB, Potosky AL, Lang K, Mallick R, Berger M, Warren JL. Identifying cancer relapse using SEER-Medicare data. Med Care. 2002;40(8 Suppl):IV-75-81.

32. Willett WC, Blott WJ, Colditz GA, Folsom AR, Henderson BE, Stampfer MJ. Merging and emerging cohorts. Not worth the wait. Nature. 2007;445(7125):257-8.

33. Australian Institute of Health and Welfare, Cancer Australia. Breast cancer in Australia: an overview. Canberra: Australian Institute of Health and Welfare; 2012 [cited 2015 Oct 29]. Available from: www.aihw.gov.au/ WorkArea/DownloadAsset.aspx?id=10737423006

34. Nixon AJ, Neuberg D, Hayes DF, Gelman R, Connolly JL, Schnitt S, et al. Relationship of patient age to pathologic features of the tumor and prognosis for patients with stage I or II breast cancer. J Clin Onc. 1994;12(5):888-94.

\section{Copyright: (c)}

(C) 2016 Kemp-Casey et al. This article is licensed under the Creative Commons Attribution-NonCommercial-ShareAlike 4.0 International Licence, which allows others to redistribute, adapt and share this work non-commercially provided they attribute the work and any adapted version of it is distributed under the same Creative Commons licence terms. See: www.creativecommons.org/licenses/by-nc-sa/4.0/ 